\title{
Complement Protein C1q and Adiponectin Stimulate Mer Tyrosine Kinase-Dependent Engulfment of Apoptotic Cells through a Shared Pathway
}

\author{
Manuel D. Galvan ${ }^{\mathrm{a}-c}$ Holly Hulsebus ${ }^{\mathrm{a}}$ Thomas Heitker ${ }^{\mathrm{b}, c}$ Erliang Zeng ${ }^{c, d}$ \\ Suzanne S. Bohlson ${ }^{\mathrm{a}-\mathrm{c}}$ \\ a Department of Microbiology and Immunology, Des Moines University, Des Moines, lowa, ${ }^{b}$ Department of \\ Microbiology and Immunology, Indiana University School of Medicine - South Bend, South Bend, Ind., \\ cDepartment of Biological Sciences, Eck Institute for Global Health, and ${ }^{\mathrm{d}}$ Department of Computer Science \\ and Engineering, University of Notre Dame, Notre Dame, Ind., USA
}

\section{Key Words \\ C1q $\cdot$ Mer tyrosine kinase - Efferocytosis - Lupus . \\ Complement $\cdot$ Macrophages $\cdot$ Phagocytosis}

\begin{abstract}
The failure to clear apoptotic cells is linked to defects in development and autoimmunity. Complement component $\mathrm{C} 1 \mathrm{q}$ is required for efficient engulfment of apoptotic cells (efferocytosis), and C1q deficiency leads to the development of lupus. We recently identified a novel molecular mechanism for C1q-dependent efferocytosis in murine macrophages. C1q elicited the expression of Mer tyrosine kinase (Mer), a receptor that regulates efficient efferocytosis and prevention of autoimmunity. To characterize the C1q-dependent signal transduction mechanism, pathway analysis of the transcriptome from C1q-activated macrophages was performed, and it identified the adiponectin signaling pathway as significantly upregulated with C1q. Adiponectin is structurally homologous to $\mathrm{C} 1 \mathrm{q}$ and regulates cellular metabolism via downstream activation of 5'adenosine monophosphate-activated protein kinase (AMPK). Macrophage stimulation with $\mathrm{C} 1 \mathrm{q}$ resulted in the activation of AMPK, and silencing of AMPK expression using siRNA-inhibited C1 q-de-
\end{abstract}

pendent efferocytosis. Adiponectin signaling also stimulates activation of nuclear receptors, and inhibition of the nuclear receptor retinoid $\mathrm{X}$ receptor abrogated $\mathrm{C} 1 \mathrm{q}$-dependent Mer expression and efferocytosis. Furthermore, adiponectin elicited Mer expression and Mer-dependent efferocytosis in macrophages similar to cells stimulated with C1q. Collective$\mathrm{ly}$, our results suggest that $\mathrm{C} 1 \mathrm{q}$ and adiponectin share a common signal transduction cascade to promote clearance of apoptotic cells, and identify a novel molecular pathway required for efficient efferocytosis.

c 2014 S. Karger AG, Basel

\section{Introduction}

C1q, the recognition component of the classical complement pathway belongs to a family of proteins called defense collagens. Defense collagens are innate pattern-recognition molecules that share similar structural features: a C-terminal globular head region and an extended N-terminal collagen-like tail $[1,2]$. Family members include mannose-binding lectin (MBL), surfactant protein (SP)-A, SP-D and ficolin. Defense collagens regulate phagocyte activity including the engulf-

\section{KARGER}

(c) 2014 S. Karger AG, Basel

1662-811X/14/0066-0780\$39.50/0

E-Mail karger@karger.com

www.karger.com/jin
Dr. Suzanne S. Bohlson

Department of Microbiology and Immunology

Des Moines University

3200 Grand Avenue, Des Moines, Iowa 50312-4198 (USA)

E-Mail suzanne.bohlson@dmu.edu 
ment of apoptotic cells, a process that is referred to as 'efferocytosis' [2, 3].

Defective efferocytosis is associated with the development of autoimmunity because apoptotic cells that are not cleared efficiently undergo secondary necrosis and become a source of neoantigens that are highly immunogenic [4-8]. For example, apoptotic cells are considered an important source of autoantigen in lupus, and deficiency in $\mathrm{C} 1 \mathrm{q}$ results in a defect in engulfment of apoptotic cells and the development of lupus in greater than $90 \%$ of affected individuals $[3,9]$. Therefore, identification of mechanisms required for efficient efferocytosis may provide new molecular targets for the treatment or prevention of lupus or other autoimmune/inflammatory diseases. We recently identified a novel molecular mechanism for C1q-dependent efferocytosis in murine macrophages [10]. Specifically, we found that C1q elicited macrophage expression of the efferocytic receptor-ligand pair; Mer tyrosine kinase (Mer) and growth arrest factor 6 (Gas 6). Moreover, C1q-dependent Mer expression in macrophages resulted in enhanced efferocytosis. MBL, a defense collagen homologous to C1q, failed to upregulate Mer and Gas 6 expression.

Although defense collagens share similar structural features, multiple defense collagens (e.g. SP-A, SP-D, MBL and ficolin) also fall within the 'collectin' family because they contain collagen-like tails and C-type lectin domains within the globular head region. While $\mathrm{Clq}$ is structurally related to the collectins, the globular head region is not a C-type lectin domain, but rather it contains a compact jelly-roll $\beta$-sandwich fold typical of tumor necrosis factor (TNF) family members [11]. Seventeen family members with similar structures have now been described as C1q/TNF-related proteins (CTRP), and these molecules may have similar functions in the regulation of metabolic activity [12]. Among the CTRP family members is the adipokine, adiponectin. $\mathrm{Clq}$ is structurally more similar to adiponectin when compared to collectins, such as MBL, based on homology in the globular head region. Moreover, recent data suggest shared functions for $\mathrm{Clq}$ and adiponectin in innate immunity since, similar to C1q-deficiency, deficiency in adiponectin is associated with defective efferocytosis and the development of autoimmunity $[13,14]$.

Adiponectin is produced by adipocytes and is secreted into circulation where it modulates biological responses via adiponectin receptor 1 (AdipoR1), adiponectin receptor 2 (AdipoR2) or $\mathrm{T}$ cadherin (T-cad) and their downstream signaling targets $[15,16]$. More recent studies have suggested an as yet unidentified receptor on macrophages that mediates adiponectin signaling [17]. AdipoR1 and AdipoR2 are members of a new class of seven transmembrane-spanning receptors that are distinct from G-protein-coupled receptors [15]. Adiponectin receptor activation in skeletal muscle, liver and endothelial cells initiates a signaling cascade through activation of $5^{\prime}$ adenosine monophosphate-activated protein kinase (AMPK) and peroxisome proliferator-activated receptor alpha (PPARa) [18]. AMPK is a heterotrimeric molecular complex that contains a catalytic $\alpha$-subunit, and regulatory $\beta$ - and $\gamma$-subunits. Phosphorylation of a threonine residue (Thr ${ }^{172}$ ) in the $\alpha$-subunit results in AMPK activation and is mediated predominantly by CaMKK $\beta\left(\mathrm{Ca}^{2+} /\right.$ calmodulin-dependent protein kinase kinase $\beta$ ) and LKB1 (liver kinase B1) [19]. AMPK senses intracellular adenosine levels and is activated under conditions where AMP or ADP levels are elevated and ATP levels are reduced. Both AMP and ADP sustain activation of AMPK by preventing dephosphorylation of $\mathrm{Thr}^{172}$ [19]. Thus, AMPK activity is directly coupled to the energy status of the cell. While AMPK activity has been widely associated with cellular metabolism, recent studies suggest that AMPK also influences the immune response, including macrophage cytokine expression and phagocytosis. For example, AMPK knockdown attenuates LPS- and fatty acid-mediated inflammation in macrophages [20], and recent studies have shown that AMPK activation is associated with enhanced phagocytosis and macrophage polarization $[21,22]$. Similarly, C1q stimulates enhanced phagocytosis and diminution of pro-inflammatory cytokine production from myeloid cells, although the contribution of AMPK to this process has not been explored.

To begin to investigate the signal transduction cascade in myeloid cells downstream of $\mathrm{C} 1 \mathrm{q}$, we performed pathway analysis on the transcriptome of C1q-activated macrophages and identified the adiponectin signaling pathway as significantly upregulated. Therefore, we examined: (1) whether key adiponectin signaling molecules (e.g. AMPK and nuclear receptors) were involved in C1q-dependent Mer expression and (2) whether adiponectin, similar to C1q, enhanced Mer-dependent efferocytosis. The data presented herein demonstrate that AMPK, a key node in the adiponectin signaling pathway, is required for C1q-dependent Mer expression. Moreover, we report that, similar to $\mathrm{C} 1 \mathrm{q}$, adiponectin elicits Mer-dependent efferocytosis. Collectively, these results and others suggest that CTRP family members may serve as a bridge between immune system regulation and metabolic functions. 


\section{Materials and Methods}

All reagents were purchased from Fisher (Pittsburgh, Pa., USA) unless otherwise indicated. Dulbecco's modified Eagle's medium (DMEM) and RPMI 1640 were purchased from Gibco/Molecular Probes/Invitrogen (Carlsbad, Calif., USA). Serum-free media (HL1) containing a serum substitute was purchased from Fisher. Fetal bovine serum (FBS) was purchased from Hyclone Laboratories (Logan, Utah, USA) and heat inactivated for $30 \mathrm{~min}$ at $56^{\circ} \mathrm{C}$. C1q was isolated from plasma-derived normal human serum by ion-exchange chromatography, followed by size-exclusion chromatography according to the method of Tenner et al. [23], and modified as described [24]. C1q collagen-like tails were kindly provided by Dr. Andrea Tenner, University of California, Irvine, Calif., USA. C1q was heat inactivated by incubation at $56^{\circ} \mathrm{C}$ for $30 \mathrm{~min}$. Adiponectin and Mer-Fc were purchased from R\&D Systems (Minneapolis, Minn., USA). Rabbit anti-mouse Mer antibody was purchased from Santa Cruz Biotechnology Inc. (Santa Cruz, Calif., USA). Rabbit anti-mouse AMPK antibody, rabbit anti-mouse phosphor-specific AMPK antibody and rabbit anti-mouse phosphor-specific ACC were purchased from Cell Signaling (Danvers, Mass., USA). Mouse anti-actin antibody was purchased from Sigma (St. Louis, Mo., USA). HRP-conjugated secondary antibodies were purchased from Jackson ImmunoResearch (West Grove, Pa., USA). Control (Cat No. 001810-10-05) and AMPK siRNA (Cat No. L-041035-00-0005) were purchased from Thermo Scientific (West Palm Beach, Fla., USA). RNAiMAX lipofectamine was purchased from Life Technologies/Invitrogen (Carlsbad, Calif., USA). LXR agonist GW3965 and PPAR $\gamma$ were from Sigma. RXR agonist LG100268 (LG268) and PPAR $\beta$ antagonist GSK0660 were from Santa Cruz Biotechnology Inc. RXR antagonist HX531and PPAR $\gamma$ antagonist GW9662 were acquired from R\&D Systems. Compound $\mathrm{C}$ was from Calbiochem (EMD Millipore, Billerica, Mass., USA).

\section{Mice}

Adiponectin R1 knockout, adiponectin R2 knockout and T-cad knockout mouse femurs were obtained from Dr. Tamar R. Aprahamian (Boston University). LXR mutant mice were provided by Dr. Peter Tontonoz (University of California). PPAR $\gamma$ mutant mice were provided by Dr. Mary J. Thomassen (East Carolina University). PPARa mutant mice were purchased from Jackson Laboratories. All mice were on a $\mathrm{C} 57 \mathrm{Bl} / 6$ background. Mice were housed in a pathogen-free facility. All methods were approved by the University of Notre Dame and Des Moines University Institutional Animal Care and Use Committee.

\section{Cell Culture}

Bone marrow-derived macrophages (BMDM) were generated as previously described [25]. Briefly, femurs and tibias were isolated from mice and bone marrow was flushed from bones with DMEM supplemented with $2 \%$ FBS and 100 units/ml penicillin G sodium $/ 100 \mu \mathrm{g} / \mathrm{ml}$ streptomycin sulfate (Pen/Strep). Marrow was washed with PBS $10 \mathrm{mM}$ of EDTA, red cells were lysed and cells were cultured in DMEM supplemented with 10\% FBS, $10 \mathrm{mM}$ of HEPES and Pen $/$ Strep at $37^{\circ} \mathrm{C}$ and $5 \% \mathrm{CO}_{2}$ for $2-4 \mathrm{~h}$ in a pre-adhesion step to remove resident fibroblasts and macrophages. Nonadherent cells were cultured in BMDM media (DMEM, 10\% FBS, $15 \%$ L929 conditioned media, Pen/Strep and $10 \mathrm{mM}$ of HEPES pH 7.4) at $37^{\circ} \mathrm{C}$ and $5 \% \mathrm{CO}_{2}$. Following maturation for 4 days, $6 \mathrm{ml}$ of fresh media was added and the cells were considered fully mature at 7 days. Media was replenished every 2-3 days to ensure cell viability. The human Jurkat T cell line was obtained from ATTC (Manassas, Va., USA) and maintained in RPMI supplemented with $10 \%$ FBS and Pen/Strep. Murine thymocytes were harvested from C57BL/6 mice at 3-4 weeks of age. To generate a single cell suspension of thymocytes, thymi were placed in a sterile cell strainer (100 $\mu \mathrm{M}$ nylon mesh) and disaggregated with a $1-\mathrm{ml}$ syringe plunger. The resulting cell suspension was washed with PBS and red blood cells were lysed. Thymocytes were cultured in RPMI media supplemented with $10 \mathrm{~mm}$ of sodium hypoxanthine and $1.6 \mathrm{mM}$ of thymidine (Invitrogen). Thioglycollate-elicited peritoneal macrophages were isolated by lavage from mice $72 \mathrm{~h}$ after injection of $1 \mathrm{ml}$ of sterile $4 \%$ thioglycollate into the peritoneal cavity. Peritoneal macrophages were cultured overnight in DMEM, 5\% FBS, Pen/ Strep and $10 \mathrm{mM}$ of HEPES $\mathrm{pH} 7.4$ prior to siRNA treatment.

\section{siRNA Treatment}

Thioglycollate-elicited peritoneal macrophages were allowed to rest overnight in DMEM containing 5\% FBS, Pen/Strep and 10 $\mathrm{mM}$ of HEPES $\mathrm{pH}$ 7.4. The following day, cells were harvested and re-suspended in DMEM containing 2\% FBS without antibiotics and $3.5 \times 10^{6}$ macrophages were plated in a $35 \times 10 \mathrm{~mm}$ petri dish. The macrophages were allowed to rest for $30 \mathrm{~min}$ prior to treatment with RNAiMAX lipofectamine containing $100 \mathrm{nM}$ of siRNA for $24 \mathrm{~h}$ according to the manufacture's recommendations. The following day, the cells were treated with fresh media containing RNAiMAX lipofectamine and $100 \mathrm{nM}$ of siRNA for another $24 \mathrm{~h}$.

\section{Phagocytosis Assays}

Sheep erythrocytes sub-optimally opsonized with IgG (EAIgG) were prepared as previously described [26] and the EAIgG phagocytosis assays were performed as described [27]. Percent phagocytosis was defined as the number of macrophages ingesting at least one target divided by the total number of macrophages counted, multiplied by 100 . The phagocytic index was defined as the number of ingested targets per 100 cells counted. At least two hundred cells per well from duplicate experimental culture conditions were scored. Slides were scored by individuals blinded to treatment. Flow cytometric apoptotic cell phagocytosis assays were performed as described [27], and percent phagocytosis was defined as CD11b- and CFSE-double positive cells divided by the total CD11b-positive cells, multiplied by 100 . For microscopy-based apoptotic cell phagocytosis assays, murine thymocytes were treated with $3 \mu \mathrm{M}$ of dexamethasone (Sigma) for $5 \mathrm{~h}$ at $37^{\circ} \mathrm{C}$ in complete RPMI media supplemented with $10 \mathrm{mM}$ of sodium hypoxanthine and $1.6 \mathrm{mM}$ of thymidine (Invitrogen), washed with complete media and labeled with $5 \mu \mathrm{M}$ of CFSE (Invitrogen) for $30 \mathrm{~min}$ at $37^{\circ} \mathrm{C}$, followed by an additional wash in complete media. Untreated control cells were incubated for the same period without dexamethasone. Treatment with dexamethasone for this time period routinely yielded greater than $60 \%$ apoptotic cells as measured by Annexin V/Propidium Iodide labeling (BioVision Inc., Mountain View, Calif., USA). Eight-well Lab Tek Chamber Slides (Nalge Nunc International, Rochester, N.Y., USA) were coated with 250 $\mu \mathrm{l}$ of C1q or human serum albumin (HSA; Baxter, Deerfield, Ill., USA) at a concentration of $4 \mu \mathrm{g} / \mathrm{ml}$ and washed with PBS prior to the addition of cells. Phagocytes were re-suspended at $1.0 \times 10^{5}$ cells/ml in phagocytosis buffer (RPMI with $2 \mathrm{mM}$ of glutamine, Pen/Strep and $5 \mathrm{mM}$ of $\mathrm{MgCl}_{2}$ ), and $250 \mu \mathrm{l}$ of the cell suspension was added to the wells. Cells were allowed to adhere for $5 \mathrm{~h}$ at $37^{\circ} \mathrm{C}$ 
and $5 \% \mathrm{CO}_{2}$ prior to the addition of targets. In some conditions, soluble Mer-Fc fusion protein $(40 \mu \mathrm{g} / \mathrm{ml})$ was added to the macrophages for $1 \mathrm{~h}$ prior to the addition of targets. Apoptotic or live thymocytes were added at a 1:10 ratio of macrophage to targets, and slides were centrifuged for $3 \mathrm{~min}$ at $700 \mathrm{rpm}(98 \mathrm{~g})$, and then incubated for $1 \mathrm{~h}$ at $37^{\circ} \mathrm{C}$ and $5 \% \mathrm{CO}_{2}$. At the indicated time point, slides were washed extensively with PBS, fixed with $3.7 \%$ paraformaldehyde and stained with PE-labeled anti-mouse CD11b (eBioscience, San Diego, Calif., USA). A minimum of 200 cells per experimental condition were quantified by individuals blinded to the experimental design. The percent phagocytosis was calculated as described above.

\section{Western Blot}

BMDM were seeded at $0.5 \times 10^{6}$ cells $/ \mathrm{ml}$ in one-well Lab Tek Chamber Slides that were pre-coated with $2 \mathrm{ml}$ of $4 \mu \mathrm{g} / \mathrm{ml} \mathrm{HSA}$, $\mathrm{C} 1 \mathrm{q}$, heat-inactivated C1q, C1q collagen-like tails or adiponectin. At the indicated time point, BMDM lysates were generated with RIPA buffer ( $25 \mathrm{~mm}$ of Tris- $\mathrm{HCl}, \mathrm{pH} 7.6,150 \mathrm{mM}$ of NaCl, 1\% NP$40,1 \%$ sodium deoxycholate and $0.1 \%$ SDS) supplemented with a protease and phosphatase inhibitor cocktail tablet (Roche, Indianapolis, Ind., USA). Total protein concentration was determined by BCA according to the manufacturers' instructions (Thermo Scientific, Rockford, Ill., USA) and 10-20 $\mu$ g of protein was loaded on $7.5 \%$ SDS-PAGE under reducing conditions. Proteins were transferred to PVDF membrane and blocked either for $2 \mathrm{~h}$ or overnight. Membranes were probed with appropriate primary and secondary antibodies as indicated in the figure legends.

\section{Microarray Analysis}

Microarray and bioinformatics analyses were performed at the University of Notre Dame Genomics and Bioinformatics Core Facility. Briefly, total RNA was extracted using the TRIzol (Sigma) method from BMDM adhered to HSA or C1q for $18 \mathrm{~h}$. The resulting RNA was precipitated using sodium acetate and washed with ethanol to remove contaminants. Randomly selected RNA samples were analyzed with an Agilent 2100 Bioanalyzer to verify sample integrity prior to cDNA synthesis. Double-stranded cDNA was generated using the TransPlex Complete Whole Transcriptome Amplification Kit (Sigma) according to the manufacturer's instructions and the resulting product was precipitated with sodium acetate, washed with ethanol to remove residual primers and nucleotides, and stored at $-20^{\circ} \mathrm{C}$ until labeled. Randomly selected cDNA were analyzed with an Agilent 2100 Bioanalyzer to verify sample integrity prior to labeling. cDNA was labeled with Cy3 using NimbleGen One-Color DNA labeling kits according to the manufacturer's instructions (Roche NimbleGen Inc., Madison, Wisc., USA), lyophilized, and stored at $-20^{\circ} \mathrm{C}$ overnight. Labeled product was re-suspended in hybridization buffer containing alignment oligos and unique sample tracking controls, loaded onto a murine gene expression microarray designed by NimbleGen, and hybridized overnight. After extensive washing, the array microchips were dried and then scanned using a NimbleGen MS 200 Microarray Scanner. Array data was extracted and analyzed using NimbleScan software v.2.5. The mean fluorescence intensity was derived from a $\log _{2}$ transformation of the raw data and normalized using a quantile normalization method [28]. The data were compared for statistical significance using Student's t test and $q$ value for control of false discovery rate [29]. Pathway analysis was assessed with GeneGo databases. The data discussed in this publication have been deposited in the National Center for Biotechnology Information's (NCBI) Gene Expression Omnibus (GEO) and will be accessible through GEO Series accession No. GSE48619.

\section{Quantitative Real-Time PCR}

Total RNA was isolated as described above. Quantitative realtime PCR (qRT-PCR) reactions were assembled with SABiosciences (Frederick, Md., USA) SYBR Green qPCR Master Mix according to the manufacturer's instructions, and amplified using a Real Time PCR System from Applied Biosystems (Carlsbad, Calif., USA). All reactions were carried out in triplicate. Negative controls included reactions in which template cDNA or enzyme were omitted. The amplification specificity of the reactions was confirmed by melting-curve analysis. Results were normalized to GAPDH and reported as the relative gene expression. The primers used were: Plcb3 (forward: 5'-GGA TGA GGA GGA AGA TGA AGA AG-3'; reverse: $5^{\prime}$-AAG GAC TTG AAC TTG ACG GG-3'), Camkk1 (forward: $5^{\prime}$-TGA GAA AAG GGC CAG TCA TG C3-3'; reverse: $5^{\prime}$ GGA GTA GGT TAG ATG GCT TGA TG-3'), Pik3r1 (forward: 5'-GGA TGC TGA ATG GTA CTG GG-3'; reverse: 5' -TGA AAG AGT GTA ATC GCC GTG-3'), Itpr 1 (forward: $5^{\prime}$-GAT GTC AAA GAG GGA CAG AAG G-3'; reverse: $5^{\prime}$-GCA GCG GAG AAT GAG ATC ACC-3'), Mapk14 (forward: 5'-GTG ATT GGT CGT TTG GAT GTG-3'; reverse: ${ }^{\prime}$-TGA GAA ACT GAA CGT GGT CG-3'), GAPDH (forward: $5^{\prime}$-CCA ATG TGT CCG TCG TGG ATC-3'; reverse: $5^{\prime}$-GTT GAA GTC GCA GGA GAC ACC-3').

\section{Statistics}

Statistics other than microarray were performed using Prism (v.5.02; GraphPad, La Jolla, Calif., USA). Statistical comparisons between groups were performed as indicated in the figure legends.

\section{Results}

\section{C1q Activates an Intracellular Signaling Cascade Shared by Adiponectin}

While numerous studies have reported the effects of C1q on phagocyte activation [reviewed in 3], there is little known about the molecular mechanism leading to $\mathrm{C} 1 \mathrm{q}-$ dependent phagocyte activation. We recently demonstrated that $\mathrm{C} 1 \mathrm{q}$ triggers Mer-dependent efferocytosis; however, the mechanism leading to C1q-dependent Mer expression is unknown. Our previous experiments indicated that protein synthesis was required for $\mathrm{C} 1 \mathrm{q}$-dependent Mer-mediated efferocytosis [10]. Incubation of murine BMDM on C1q enhanced Mer expression as demonstrated by immunofluorescence (fig. 1a). Kinetic analysis of C1q-dependent Mer expression indicated that Mer was upregulated $3 \mathrm{~h}$ after macrophage adhesion to $\mathrm{Clq}$ (fig. 1b). Although the collagen-like tail of C1q and other defense collagens has been reported to trigger macrophage activation and phagocytosis $[30,31]$, full length native $\mathrm{Clq}$ and not the collagen tail (or heat treated C1q) 


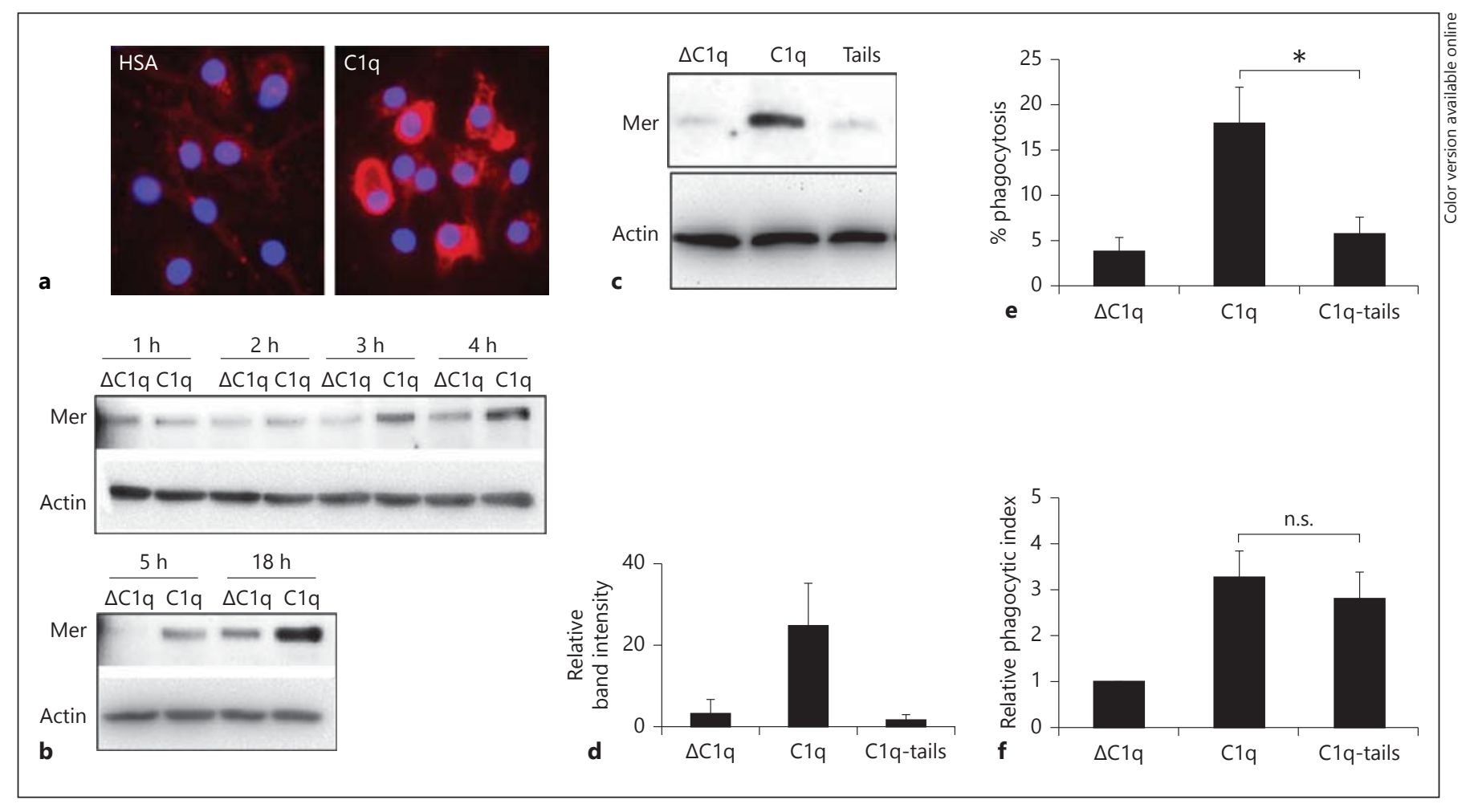

Fig. 1. Full-length $\mathrm{C} 1 \mathrm{q}$, and not the $\mathrm{C} 1 \mathrm{q}$ collagen-like tails, elicit Mer expression in mouse BMDM. a BMDM were adhered to Lab Tek chamber slides pre-coated with $4 \mu \mathrm{g} / \mathrm{ml}$ of control protein HSA or C1q for $18 \mathrm{~h}$ and analyzed for Mer expression (red; colors refer to the online version only) by immunofluorescence microscopy. Nuclei were counterstained with Dapi (blue). b BMDM were adhered to Lab Tek chamber slides pre-coated with $4 \mu \mathrm{g} / \mathrm{ml}$ of heat-inactivated $\mathrm{Clq}(\Delta \mathrm{C} 1 \mathrm{q})$ or $\mathrm{C} 1 \mathrm{q}$ for $1,2,3,4,5$ or $18 \mathrm{~h}$, lysed and analyzed for Mer expression by Western blot. c BMDM were adhered to Lab Tek chamber slides pre-coated with $10 \mu \mathrm{g} / \mathrm{ml}$ of $\Delta \mathrm{C} 1 \mathrm{q}, \mathrm{C1q}$ or $\mathrm{C1q}$ collagen-like tails for $18 \mathrm{~h}$, lysed and analyzed for Mer expression by Western blot. Actin was used as a loading control. d Western blots were quantified using ImageJ. The bars represent the average plus standard deviation of three experiments after normalizing to actin. e BMDM were adhered to protein as described in $\mathbf{c}$ and then fed CFSE-labeled apoptotic Jurkat cells at a ratio of 1:3 macrophages to apoptotic cells. Macrophages were harvested and stained with anti-CD11b-PE. Percent phagocytosis was calculated as CFSE- and CD11b-positive cells divided by the total CD11b-positive cells, multiplied by 100 . The bars represent an average plus SEM from three individual experiments. ${ }^{*} \mathrm{p}<0.05$, ANOVA.f BMDM were adhered to $10 \mu \mathrm{g} / \mathrm{ml}$ of $\Delta \mathrm{C} 1 \mathrm{q}, \mathrm{C} 1 \mathrm{q}$ or $\mathrm{C} 1 \mathrm{q}$ collagen-like tails for $30 \mathrm{~min}$ and then fed sheep EAIgG. At least 200 cells/well from duplicate wells were scored by microscopy. The phagocytic index is the number of EAIgG ingested per 100 macrophages. The bars represent the average \pm SEM of three individual experiments normalized to $\Delta$ C1q. n.s. $=$ Not significant. was required to elicit Mer expression in murine macrophages (fig. 1c, d). Moreover, as predicted, the collagenlike tails failed to elicit Mer-dependent engulfment of apoptotic cells (fig. 1e). Importantly, we verified that the C1q collagen-like tails elicited Fc-receptor-dependent phagocytosis, validating that the tails were active (fig. 1f). To identify the subset of genes specific to macrophage activation with full length native $\mathrm{C} 1 \mathrm{q}$ that could be involved in Mer expression, we stimulated macrophages with heat-inactivated $\mathrm{C1q}, \mathrm{C1}$-tails or full-length native $\mathrm{C} 1 \mathrm{q}$, and analyzed gene expression by microarray. Only those transcripts that were statistically upregulated $(\mathrm{p}<$ 0.01 , Student's t test) compared to control (heat-inacti- vated $\mathrm{C} 1 \mathrm{q}$ ) were further analyzed. The resulting data demonstrated that, compared to control, C1q-tails upregulated 129 transcripts, whereas full-length native $\mathrm{Clq}$ upregulated 661 transcripts. Of those upregulated transcripts, 101 were shared between C1q-tails and full-length native $\mathrm{Clq}$ (online suppl. fig. 1; for all online suppl. material, see www.karger.com/doi/10.1159/000363295). Pathway analysis was performed using Metacore software to identify signaling pathways activated by full-length $\mathrm{Clq}$ and not C1q-tails. Several pathways were identified, including the adiponectin signaling pathway, and expression of the pathway-specific genes identified in the microarray was validated using qRT-PCR (online suppl. fig. 1B). 
Fig. 2. $\mathrm{C} 1 \mathrm{q}$ triggers activation of $\mathrm{AMPK}$. a BMDM were rested overnight in serumfree media for $18 \mathrm{~h}$ and then treated with $4 \mu \mathrm{g} / \mathrm{ml}$ of soluble HSA or C1q for $10 \mathrm{~min}$, and cell lysates were analyzed for phosphorylated-AMPK ( $\mathrm{p}$-AMPK) by Western blot. Densitometric analysis of p-AMPK from three independent experiments. Bars represent the mean $\pm \operatorname{SEM}(\mathrm{n}=3)$. ${ }^{*} \mathrm{p}<$ 0.05 , Student's t test. $\mathbf{b}$ BMDM were rested as described in $\mathbf{a}$ and treated with HSA, $\mathrm{C} 1 \mathrm{q}$ or adiponectin for the indicated time points, and cell lysates analyzed for $\mathrm{p}$ AMPK by Western blot. c BMDM were treated as described in $\mathbf{a}$ and cell lysates were analyzed for p-ACC by Western blot.

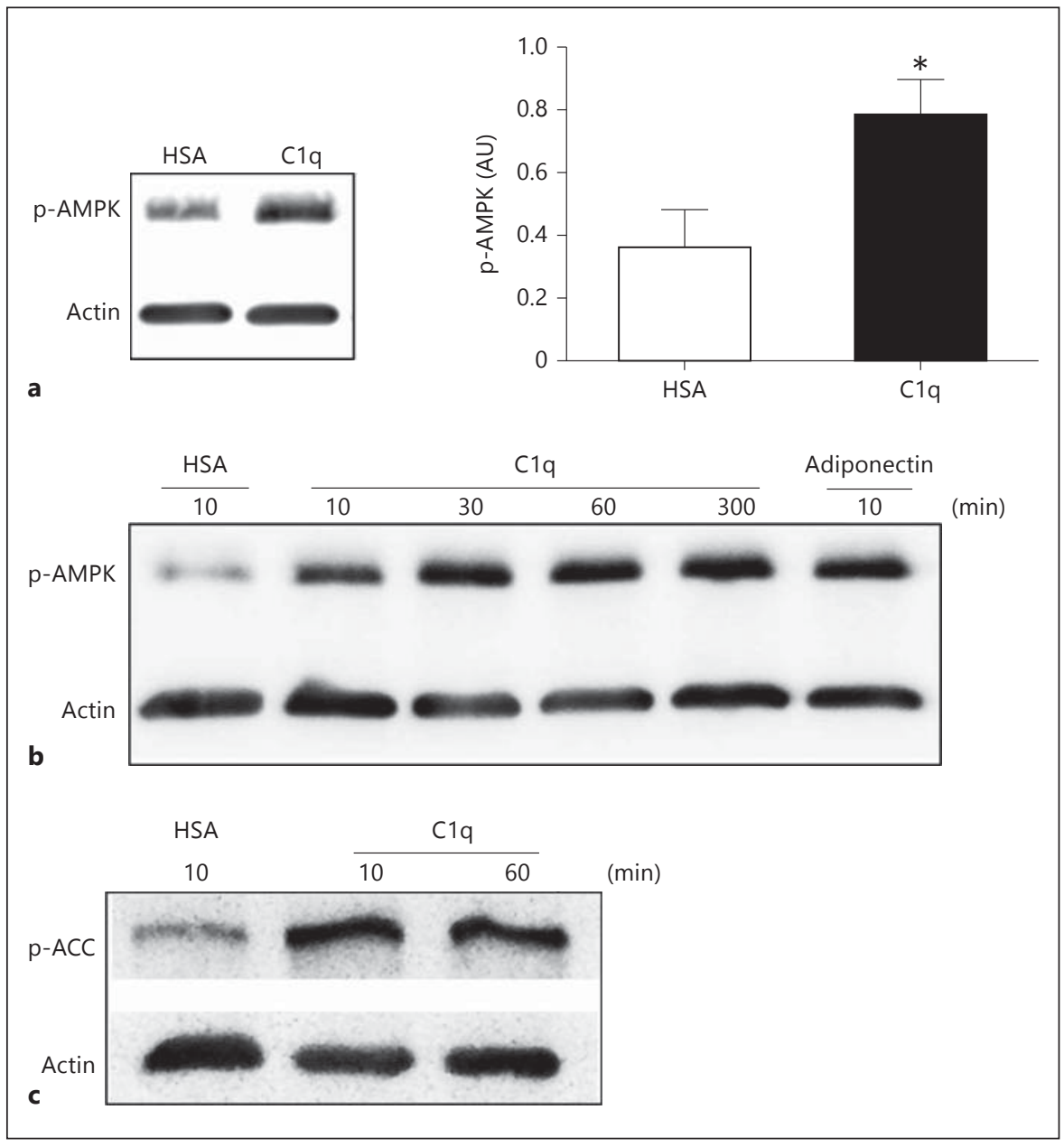

Adiponectin stimulates macrophage polarization towards an anti-inflammatory M2 macrophage, and adiponectin also stimulates enhanced efferocytosis [32, 33] (online suppl. fig. 1C). While the signal transduction pathway leading to adiponectin-dependent regulation of metabolism in muscle and liver cells has been well documented, less is known regarding the signaling mechanism utilized by adiponectin and adiponectin receptors in macrophages. Since $\mathrm{C} 1 \mathrm{q}$ and adiponectin stimulate similar activities in macrophages (downregulation of inflammation and increased efferocytosis), we sought to determine whether adiponectin and C1q utilize similar pathways to promote efferocytosis.

\section{C1q-Dependent Mer Expression Requires AMPK}

The major intracellular signaling nodes in the adiponectin signaling pathway are AMPK and PPAR $[18,34]$ (online suppl. fig. 1C). To determine whether C1q activated AMPK, BMDM were stimulated with the control protein $\mathrm{HSA}$ or $\mathrm{Clq}$ for $10 \mathrm{~min}$ and phosphorylation of AMPK at Thr ${ }^{172}$ was assessed by Western blot. As predicted, C1q triggered phosphorylation of AMPK compared to control BMDM $(0.78 \pm 0.11$ vs. $0.36 \pm 0.12$, respectively; fig. 2a). To investigate the kinetics of C1q-dependent AMPK phosphorylation, BMDM were stimulated with $\mathrm{Clq}$ for increasing amounts of time. AMPK phosphorylation was detected from C1q-stimulated macrophages after $10 \mathrm{~min}$, and phosphorylation was maintained for at least $5 \mathrm{~h}$ (fig. 2b). As expected, adiponectin-stimulated BMDM also showed increased AMPK phosphorylation compared to control BMDM (fig. 2b). Acetyl-CoA carboxylase (ACC) 1 is a substrate of AMPK that regulates fatty acid metabolism, and phosphorylation of ACC by AMPK inhibits the enzymatic activity of ACC. To verify that an increase in AMPK activity correlated with the increase in AMPK phosphorylation, the phosphorylation state of ACC was assessed by Western blot. As predicted, C1q-stimulated BMDM dis- 
Fig. 3. C1q-dependent Mer expression and efferocytosis are AMPK dependent. a BMDM were pre-treated with Compound $\mathrm{C}$ for $1 \mathrm{~h}$ and then stimulated with $4 \mu \mathrm{g} / \mathrm{ml}$ of HSA or C1q for an additional $5 \mathrm{~h}$, and cell lysates analyzed for phosphorylated-AMPK ( $\mathrm{p}$-AMPK) by Western blot. b BMDM were treated as described in a and cell lysates analyzed for Mer by Western blot. c AMPK was silenced in peritoneal macrophages with siRNA. d Peritoneal macrophages were treated with control or AMPK siRNA prior to stimulation with $4 \mu \mathrm{g} / \mathrm{ml}$ of HSA or C1q and cell lysates were analyzed for Mer by Western blot. e Peritoneal macrophages were treated as described in $\mathbf{d}$ and then fed apoptotic thymocytes at a 1:10 macrophage to apoptotic cell ratio for 1 h. ${ }^{* *} \mathrm{p}<0.01$, two-way ANOVA, Bonferroni multiple comparison tests. n.s. $=$ Not significant.

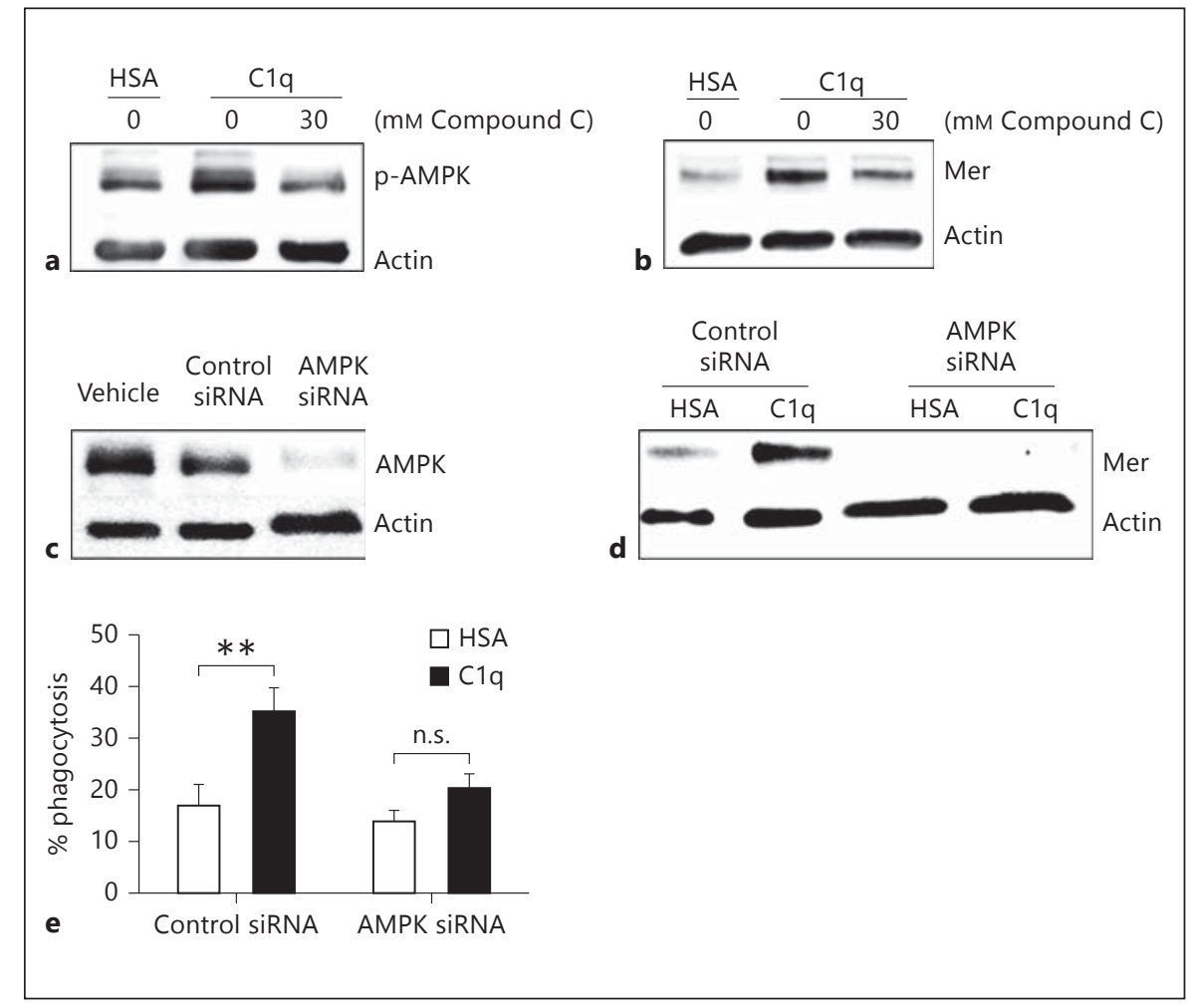

played increased ACC phosphorylation compared to control BMDM (fig. 2c). These results demonstrated that $\mathrm{C} 1 \mathrm{q}$ stimulation leads to activation of AMPK in murine macrophages.

To determine if AMPK activity was required for $\mathrm{Clq}$ dependent Mer expression, BMDM were pre-treated with the specific AMPK inhibitor, Compound $\mathrm{C}$, then stimulated with control protein or $\mathrm{Clq}$ for $5 \mathrm{~h}$, and $\mathrm{Mer}$ expression was assessed by Western blot. As predicted, treatment with Compound C blocked C1q-dependent phosphorylation of AMPK (fig. 3a) and C1q-dependent Mer expression (fig. 3b). To validate these results, AMPK expression was silenced in thioglycollate-elicited peritoneal macrophages using siRNA (fig. 3c). In the absence of AMPK, C1q failed to upregulate Mer expression (fig. 3d). These results indicated that AMPK activation and expression were required for C1q-dependent upregulation of Mer. Next we assessed whether silencing of AMPK using siRNA inhibited C1q-dependent efferocytosis. As predicted, inhibition of AMPK via siRNA inhibited C1q-dependent efferocytosis compared to thioglycollate-elicited peritoneal macrophages treated with control siRNA (fig. 3e). Silencing AMPK did not affect basal efferocytosis in this system (fig. 3e; HSA control), demonstrating that the effect was specific to C1q-dependent efferocyto- sis. Together, these data demonstrate that C1q activates an intracellular signaling cascade that requires AMPK to elicit Mer-dependent efferocytosis.

\section{RXR Regulates C1q-Dependent Mer Expression}

In addition to AMPK, PPAR $\alpha$ mediates downstream functions of adiponectin [18]. PPARa is a transcription factor belonging to the nuclear receptor superfamily that forms an obligate heterodimer with RXR. Previous studies have shown that activation of nuclear receptors such as PPAR $\gamma / \delta, \mathrm{LXR} \alpha / \beta$ and RXR $\alpha$ leads to increased expression of engulfment receptors such as Mer, Gas 6 and milk fat globule epidermal 8 [35-38]. Since RXRa has been implicated in driving Mer expression during efferocytosis [36], and since PPARa and the nuclear receptors involved in modulating expression of engulfment proteins couple to RXR as heterodimers, we utilized HX531, a global RXR antagonist, to determine whether inhibition of RXR blocked C1q-dependent Mer expression. HX531 inhibited C1q-dependent Mer expression as well as C1q-dependent efferocytosis (fig. $4 \mathrm{a}, \mathrm{b}$ ). Importantly, HX531 did not alter C1q-dependent FcR-mediated phagocytosis, demonstrating that the effects of HX531 were specific to apoptotic cell clearance and not a global inhibitor of phagocytosis (fig. 4c). Together, 


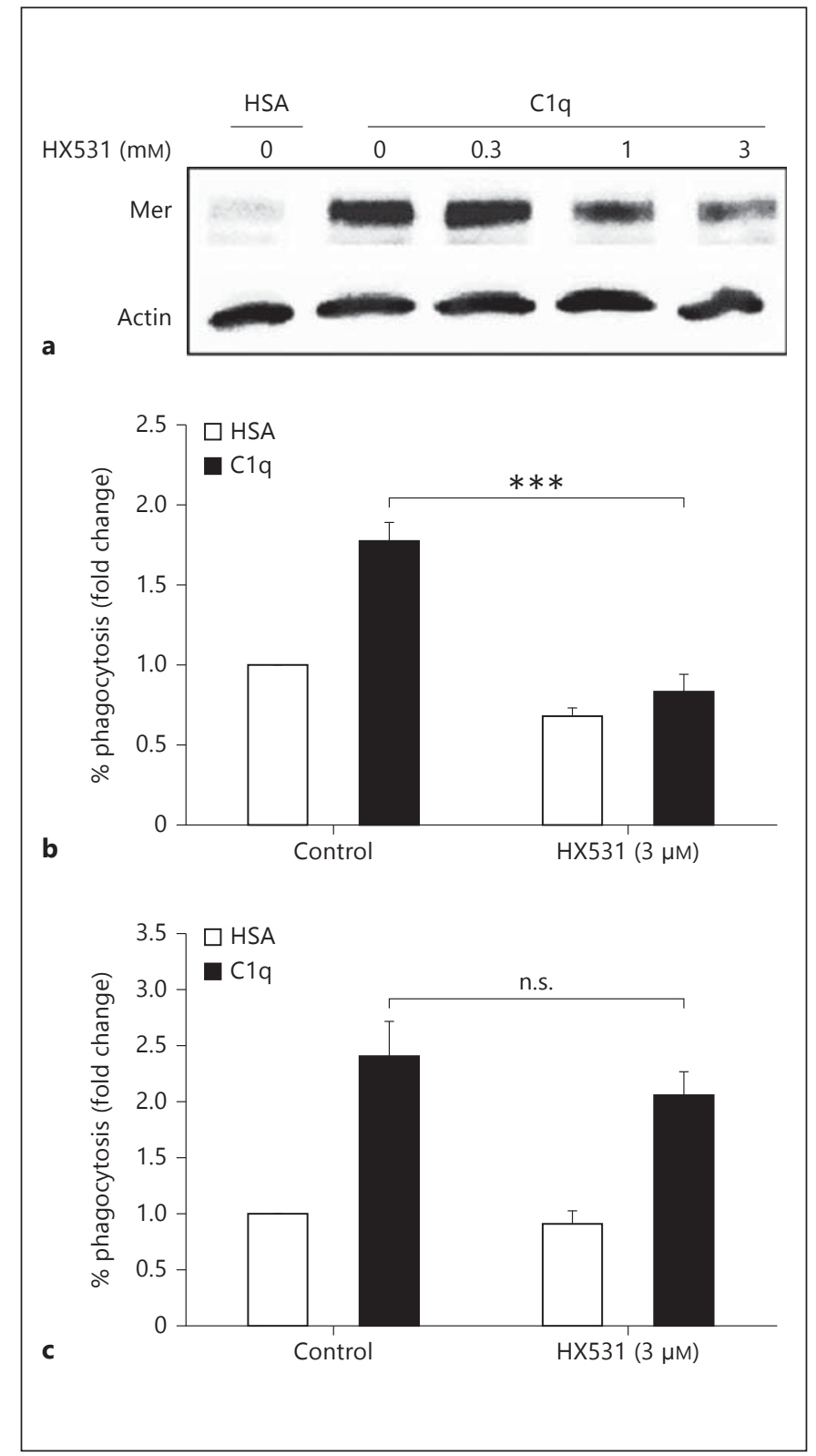

Fig. 4. RXR regulates C1q-dependent Mer expression and efferocytosis. a Macrophages were pre-treated with increasing concentrations of HX531 for $4 \mathrm{~h}$ and then adhered to chamber slides pre-coated with $4 \mu \mathrm{g} / \mathrm{ml} \mathrm{HSA}$ or C1q for $4 \mathrm{~h}$, and cell lysates were analyzed for Mer expression by Western blot. b Macrophages were treated as described in $\mathbf{a}$ and then fed apoptotic Jurkat cells at a 1:3 macrophage to apoptotic cell ratio for $1 \mathrm{~h}$. Data are expressed as fold change in phagocytosis relative to control. Bars represent the mean \pm SEM $(\mathrm{n}=3)$. ${ }^{* * *} \mathrm{p}<0.001$, two-way ANOVA, one-way ANOVA, Bonferroni multiple comparison tests. $\mathbf{c}$ Macrophages were treated as described in $\mathbf{a}$ and $\mathbf{b}$ and then fed antibody-coated red blood cells for $30 \mathrm{~min}$. Data are expressed as fold change in phagocytosis relative to control. Bars represent the mean $\pm \operatorname{SEM}(n=3)$.

C1q and Adiponectin Enhance

Efferocytosis via MerTK

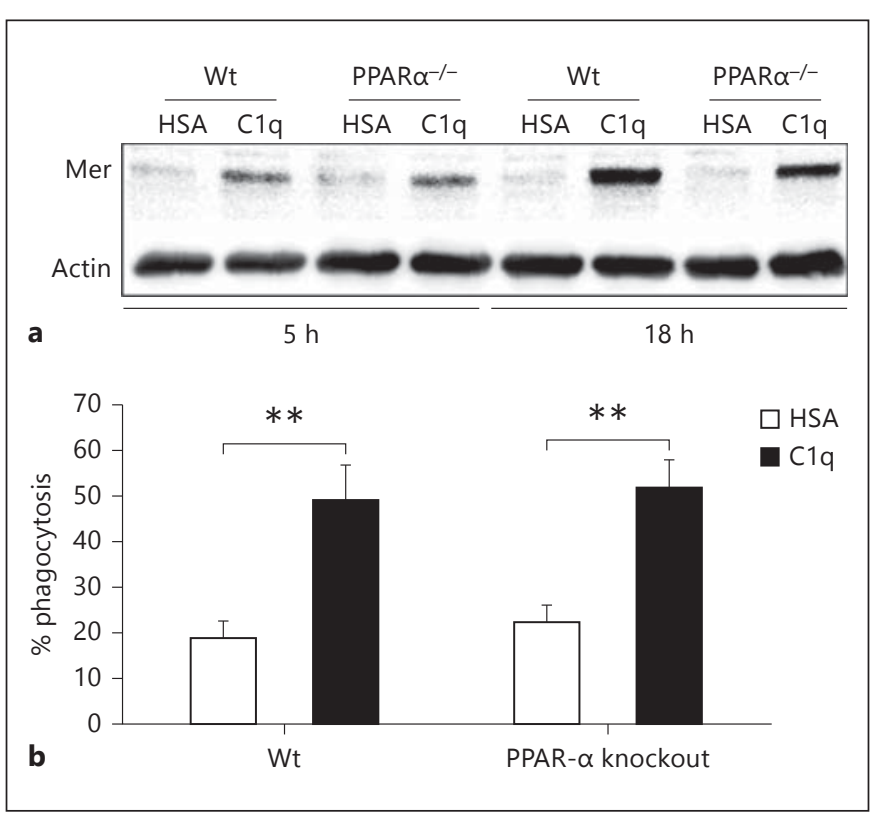

Fig. 5. C1q elicits Mer expression and efferocytosis independent of PPARa. a Wild-type (Wt) or PPARa KO BMDM were stimulated with HSA or C1q for 5 or $18 \mathrm{~h}$, and cell lysates were analyzed for Mer by Western blot. b Wild-type or PPARa KO BMDM were stimulated with HSA or C1q for $18 \mathrm{~h}$ and then fed apoptotic thymocytes at a 1:10 macrophage to apoptotic cell ratio for $1 \mathrm{~h} .{ }^{* *} \mathrm{p}<$ 0.01, two-way ANOVA, Bonferroni multiple comparison tests. n.s. $=$ Not significant.

these data suggest that $\mathrm{C1q}$ utilizes RXR to elicit Merdependent efferocytosis.

To investigate whether PPARa was involved in C1qdependent Mer expression, we utilized PPARa-deficient BMDM. Stimulation of PPARa-deficient BMDM with $\mathrm{C} 1 \mathrm{q}$ resulted in increased Mer expression (fig. 5a). Moreover, PPARa-deficient BMDM stimulated with C1q for $18 \mathrm{~h}$ showed increased efferocytosis of apoptotic thymocytes to the same extent as wild-type BMDM stimulated with C1q (fig. 5b). These results demonstrate that PPARa is not required for $\mathrm{C} 1 \mathrm{q}$-dependent Mer expression. To investigate the role of other PPARs (i.e. PPAR $\gamma$ and $\delta / \beta$ ) in $\mathrm{C} 1 \mathrm{q}$-dependent Mer expression, BMDM were pretreated with GSK0660 or GW9662, specific PPAR $\delta / \beta$ and PPAR $\gamma$ inhibitors, respectively. Inhibitor-treated macrophages were then stimulated with $\mathrm{C} 1 \mathrm{q}$ and Mer expression was assessed by Western blot. Neither GSK0060 nor GW9662 inhibited C1q-dependent Mer expression (data not shown). Additional experiments in PPAR $\gamma$-deficient mice confirmed that PPAR $\gamma$ was not required for C1q-dependent Mer expression (online suppl. fig. 2A). Collectively, these data suggest that 
Fig. 6. Adiponectin elicits Mer expression and efferocytosis. a BMDM were stimulated with $4 \mu \mathrm{g} / \mathrm{ml}$ of HSA, C1q or adiponectin for $18 \mathrm{~h}$, and cell lysates were analyzed for Mer by Western blot. b Macrophages were treated as described in a for $5 \mathrm{~h}$ and then fed apoptotic Jurkat cells at a 1:3 macrophage to apoptotic cell ratio for an additional $1 \mathrm{~h}$. Bars represent the mean \pm $\operatorname{SEM}(\mathrm{n}=3) .{ }^{*} \mathrm{p}<0.05,{ }^{* *} \mathrm{p}<0.01$, oneway ANOVA, Bonferroni multiple comparison tests. c BMDM were treated as described in $\mathbf{a}$ and $\mathbf{b}$ for $5 \mathrm{~h}$ after which MerFc was added for $1 \mathrm{~h}$ and then fed apoptotic mouse thymocytes at a $1: 10$ macrophage to apoptotic cell ratio for $1 \mathrm{~h}$. Bars represent the mean $\pm \operatorname{SEM}(n=3)$. *** $\mathrm{p}<0.001$, two-way ANOVA, Bonferroni multiple comparison tests. A minimum of 200 cells per experimental condition were quantified. d BMDM were pretreated with $3 \mu \mathrm{M}$ of HX531 and then stimulated with $4 \mu \mathrm{g} / \mathrm{ml}$ of HSA, C1q or adiponectin for $5 \mathrm{~h}$, and cell lysates were analyzed for Mer expression by Western blot. e BMDM from wt, AdipoR1 KO, AdipoR2 KO, T-cad KO or LRP KO were stimulated as in $\mathbf{a}$, and Mer expression was detected by Western blot. $\mathrm{KO}=$ Knockout; $\mathrm{Wt}=$ wild-type; $\mathrm{LRP}=$ lipoprotein-related receptor protein 1 .

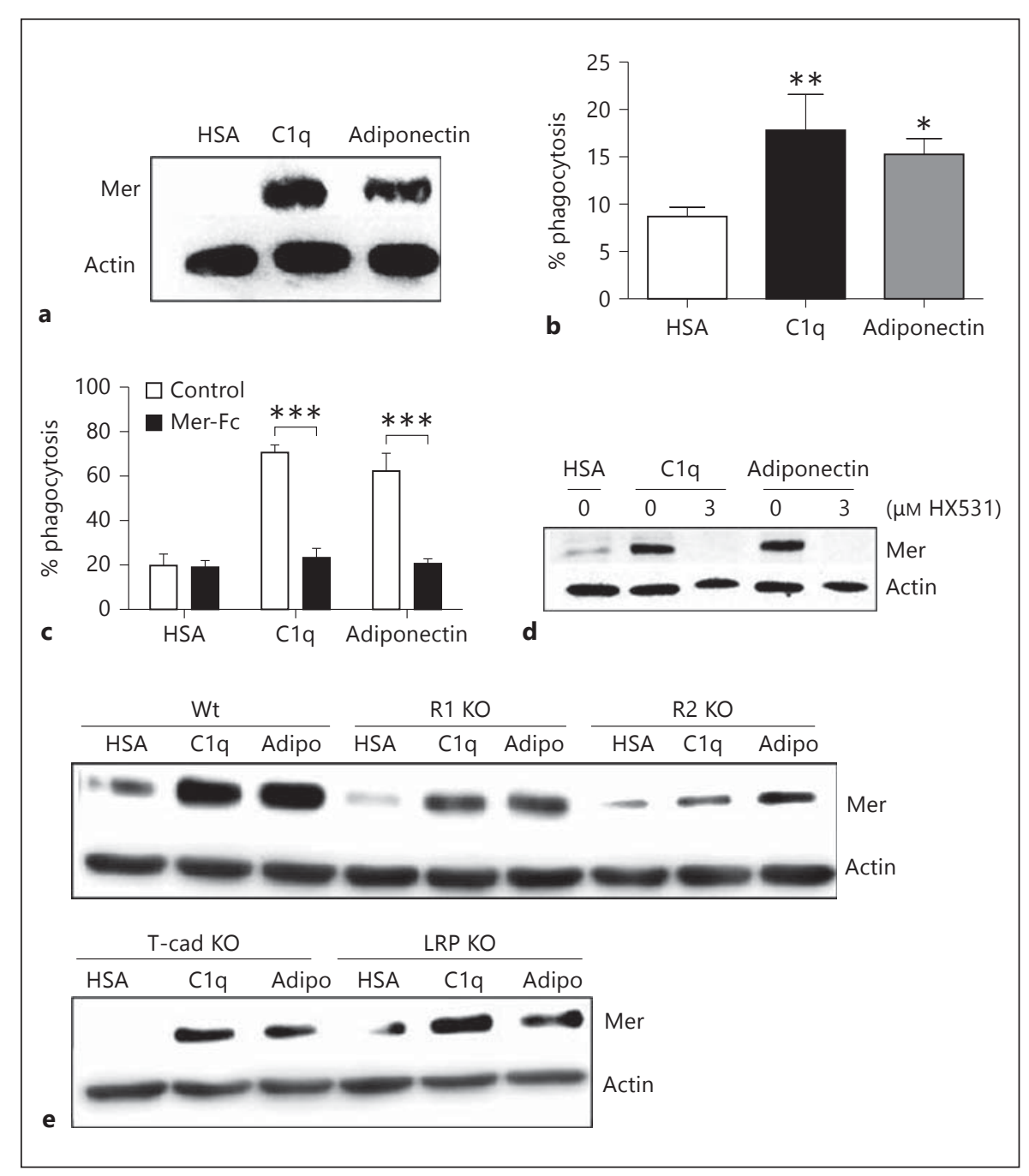

PPARs are not required for C1q-dependent Mer expression in murine BMDM.

Similar to C1q, activation of LXR leads to increased Mer expression and efferocytosis [39]. Therefore, we utilized LXR $\alpha \beta$-deficient BMDM to determine if LXR was required for $\mathrm{Clq}$-dependent Mer expression. As expected, Mer expression was upregulated with the LXR agonists GW3965 in wild-type BMDM but not in LXR-deficient BMDM (online suppl. fig. 2B). Furthermore, the RXR agonist LG100268 triggered Mer expression in wildtype BMDM and not LXR $\alpha \beta$-deficient BMDM. However, C1q elicited Mer expression in LXR $\alpha \beta$-deficient BMDM, indicating that this receptor was not required for C1qdependent Mer expression (online suppl. fig. 2B). In agreement with our previous observations, pharmacological inhibition of RXR with the RXR antagonist (HX531) inhibited C1q-dependent Mer expression in both wild- type and LXR $\alpha \beta$-deficient macrophages (online suppl. fig. 2B). Together, these data suggest that LXR $\alpha \beta$ is not required for C1q-dependent Mer expression in murine BMDM.

\section{Adiponectin Elicits Mer Expression to Promote Clearance of Apoptotic Cells}

Our results indicated that $\mathrm{C} 1 \mathrm{q}$ and adiponectin shared a common signaling mechanism involving AMPK; however, the pathway is independent of PPARa. To verify that the signaling cascade was shared between $\mathrm{Clq}$ and adiponectin, we tested the ability of adiponectin to enhance Mer-dependent efferocytosis. As predicted, adiponectin enhanced Mer expression (fig. 6a) and efferocytosis (fig. 6b). To determine whether the enhanced efferocytosis observed in BMDM upon stimulation with adiponectin was Mer dependent, we utilized a Mer-Fc 
fusion protein to compete for Mer ligands in solution. BMDM were stimulated with adiponectin or $\mathrm{Clq}$ for $5 \mathrm{~h}$ and then cultured in the presence or absence of recombinant Mer-Fc fusion protein for $1 \mathrm{~h}$ prior to co-culture with apoptotic thymocytes. As predicted, adiponectin enhanced engulfment of apoptotic thymocytes over control (62 \pm 8.1 vs. $19 \pm 5.0$; fig. $6 c)$ and Mer-Fc inhibited adiponectin-dependent efferocytosis to control levels $(20 \pm 2.8$ vs. $19 \pm 3.4$; fig. 6 c). In addition, pre-treatment of BMDM with the RXR antagonist HX531 inhibited adiponectin-dependent Mer expression compared to control BMDM (fig. 6d), further suggesting that adiponectin and $\mathrm{C} 1 \mathrm{q}$ utilize a common signaling pathway to enhance efferocytosis.

To determine whether $\mathrm{C} 1 \mathrm{q}$ and adiponectin utilized a known receptor for Mer-dependent efferocytosis, we evaluated $\mathrm{Clq}$ and adiponectin-dependent Mer expression in mouse macrophages lacking the previously described adiponectin receptors AdipoR1, AdipoR2, T-cad and LRP. C1q and adiponectin elicited Mer expression above control levels in all of the mouse macrophages examined, indicating that these receptors were not required for C1q-dependent Mer expression (fig. 6e). Collectively, these data suggest that there is an unidentified C1q/adiponectin receptor on macrophages required for Mer expression.

\section{Discussion}

C1q has been shown to play a critical role in efferocytosis and prevention of autoimmunity in human patients and murine autoimmune disease models [9, 36, 37]. Previous studies demonstrated that $\mathrm{Clq}$ enhances efferocytosis via activation of the classical complement pathway and ingestion via complement receptors, or alternatively by directly bridging apoptotic cells to phagocytes [reviewed in 3]. More recently, we demonstrated that, in addition to these mechanisms, $\mathrm{C} 1 \mathrm{q}$ enhances Mer expression and Mer-dependent efferocytosis [10]. In the present study, we extended those observations and demonstrated for the first time that C1q utilizes AMPK to elicit Mer expression and Mer-dependent efferocytosis in murine BMDM. Moreover, this is the first study to report that adiponectin, a protein structurally homologous to $\mathrm{C} 1 \mathrm{q}$, enhances Mer expression and Mer-dependent efferocytosis. Together, these data reveal a shared signaling mechanism for $\mathrm{Clq}$ and adiponectin that is important in the regulation of efferocytosis and may be involved in autoimmunity.

C1q and Adiponectin Enhance

Efferocytosis via MerTK
Previous studies have shown that adiponectin enhances apoptotic cell clearance. Adiponectin was shown to bind directly to apoptotic cells and to macrophages via calreticulin [32]. Thus, in this context, adiponectin bridges apoptotic cells to macrophages and thereby enhances efferocytosis. This bridging mechanism is independent of adiponectin receptors (AdipoR1, AdipR2 and T-cad) and dependent on a phagocytic complex of calreticulin with the transmembrane protein LRP (CD91) [32]. This bridging mechanism is also shared with $\mathrm{C} 1 \mathrm{q}$ [reviewed in 3]. In addition, adiponectin deficiency, similar to $\mathrm{C} 1 \mathrm{q}$ deficiency, accelerates the onset and severity of the autoimmune phenotype observed in autoimmune-susceptible murine strains $[13,40]$. Herein, we provide evidence demonstrating that, in addition to acting as bridging molecules to enhance efferocytosis via calreticulin/LRP [32], both C1q and adiponectin enhance efferocytosis by upregulating Mer. Our previous studies and the data presented here demonstrate that this Mer-dependent efferocytosis pathway is independent of LRP and therefore distinct from the previously reported bridging mechanism shared between $\mathrm{C} 1 \mathrm{q}$ and adiponectin $[10,32]$. Taken together these data demonstrate that $\mathrm{C} 1 \mathrm{q}$ and adiponectin utilize multiple common molecular mechanisms to enhance efferocytosis.

$\mathrm{C} 1 \mathrm{q}$ and adiponectin share common structural features, such as size, domains and the ability to form functional multimeric structures. Both proteins share a short $\mathrm{N}$-terminal domain, a collagen-like repeating sequence (glycine-X-Y) and a C-terminal globular domain with homology to the TNF family [41]. These structural features set them apart from members of the collectin family, such as MBL and SP-A, which contain a C-terminal lectin domain. Although collectin family members, including MBL, have been shown to enhance efferocytosis by acting as bridging molecules [42-48], our previous published studies demonstrated that MBL does not alter Mer expression and Mer-dependent efferocytosis [10]. These data suggest that the ability to upregulate Mer-dependent efferocytosis is unique to $\mathrm{Clq}$ and adiponectin, and not shared by other members of the defense collagen family. Since adiponectin and C1q share structural features that are common to members of the CTRP family [12], it is possible that other members of the CTRP family may also upregulate Mer to promote efferocytosis. While many actions of adiponectin are attributed to signaling via AdipoR1 and AdipoR2, we demonstrate here that adiponectin and C1q-dependent upregulation of Mer is independent of these receptors, and suggest that an unidentified adiponectin/C1q receptor is present on macrophages. Awazawa et al. [17] previously proposed 
the presence of an unidentified adiponectin receptor required for adiponectin-dependent regulation of IL- 6 production from macrophages, and our results provide additional evidence for the existence of such a receptor.

Identification of the molecular mechanism(s) required for cellular activation with $\mathrm{C1q}$ has been largely elusive. Although several putative $\mathrm{C} 1 \mathrm{q}$ receptors have been reported to mediate the biological effects of $\mathrm{Clq}$, there is much controversy in the field. More recently, studies suggest that $\mathrm{Clq}$ bridges apoptotic cells to phagocytes via SCARF1 [49]. This mechanism appears to be important in dendritic and endothelial cells, but to a lesser extent in macrophage-mediated efferocytosis. Together, these studies highlight the diversity of mechanisms that mediate efferocytosis.

Using microarray and pathway analysis as a means to identify a signaling pathway in macrophages downstream of $\mathrm{Clq}$, we have identified a new, and potentially targetable, molecular mechanism for C1q-dependent upregulation of Mer and efferocytosis. In agreement with recent publications reporting a distinct non-redundant role for AMPK and RXR in efferocytosis [22, 36, 50], the data presented herein demonstrate that $\mathrm{Clq}$ enhances Mer-dependent efferocytosis through RXR and AMPK. Both of these signaling molecules are involved in regulating metabolism, and a growing body of evidence suggests a link between metabolism and immune cell function including efferocytosis [51]. For example, studies have shown that alterations in mitochondrial membrane potential regulate efferocytosis [52]. Increased expression of uncoupling protein 2, which is associated with decreased mitochondrial membrane potential, results in enhanced efferocytosis. Moreover, deletion of uncoupling protein 2 results in decreased efferocytosis in macrophages in vitro and defects in apoptotic cell clearance in the thymus and testes. Similarly, AMPK, a protein central to metabolism, has also been implicated in efferocytosis. Studies have shown that pharmacological activation of AMPK enhances efferocytosis $[22,50]$. The data presented herein extend those findings and demonstrate that Mer is an AMPK target gene involved in C1q-dependent efferocytosis. Although the mechanism by which AMPK regulates expression of Mer in macrophages stimulated with $\mathrm{C} 1 \mathrm{q}$ is yet undefined, studies have shown that in addition to its rapid effects on metabolic pathways, AMPK exhibits long-term effects by regulating transcription [53]. Macrophages utilize transcription factors such as RXR to sense their lipid microenvironment and alterations of the lipid microenvironment influence metabolic demands, which in turn can influence immune responses [54]. Ac-

cordingly, these data suggest that $\mathrm{C} 1 \mathrm{q}$ may drive macrophage effector functions, such as efferocytosis, by altering lipid metabolism. Further studies are needed to determine whether there is a functional link between $\mathrm{Clq}$ and lipid metabolism in macrophages. Our continued investigations are directed towards understanding the influence of C1q on lipid metabolism, and the crosstalk between AMPK and RXR in this system. In addition, future studies are required to determine the signaling pathway upstream of RXR and whether RXR drives Mer expression independent of other nuclear receptors.

In conclusion, we have identified a novel engulfment mechanism utilized by the defense collagens $\mathrm{Clq}$ and adiponectin. C1q utilizes AMPK and nuclear receptors to upregulate Mer-dependent engulfment of apoptotic cells. This pathway is independent of the collagen-like tails, and not shared with other defense collagens such as MBL. These data identify a molecular pathway that may be useful for targeted therapeutics in autoimmune diseases. Furthermore, the structural homology between $\mathrm{C} 1 \mathrm{q}$ and adiponectin, and identification of a shared molecular mechanism in innate immunity, suggests that C1q may share other functions in metabolism that have been well characterized for adiponectin. Future studies will focus on $\mathrm{C} 1 \mathrm{q}$ and related molecules in metabolism and immunity that will contribute to our understanding of autoimmunity, inflammation and metabolic disorders.

\section{Acknowledgements}

The authors are grateful to Nicholas Burly, Emily Smith and Ronald Smith for their excellent technical support, and to Dr. Andrea Tenner for providing C1q-tails. This work was supported by NIH NIAID R56 AI099010 and ICTSI NIH/NCRR grant No. RR025761 to S.S.B.

References

J Innate Immun 2014;6:780-792 DOI: $10.1159 / 000363295$
1 Bohlson SS, Fraser DA, Tenner AJ: Complement proteins $\mathrm{Clq}$ and $\mathrm{MBL}$ are pattern recognition molecules that signal immediate and long-term protective immune functions. Mol Immunol 2007;44:33-43.

-2 Fraser DA, Tenner AJ: Directing an appropriate immune response: the role of defense collagens and other soluble pattern recognition molecules. Curr Drug Targets 2008;9:113-122.

-3 Galvan MD, Greenlee-Wacker MC, Bohlson SS: C1q and phagocytosis: the perfect complement to a good meal. J Leukoc Biol 2012;92: 489-497.

4 Erwig LP, Henson PM: Immunological consequences of apoptotic cell phagocytosis. Am J Pathol 2007;171:2-8. 
5 Munoz LE, Peter C, Herrmann M, Wesselborg S, Lauber K: Scent of dying cells: the role of attraction signals in the clearance of apoptotic cells and its immunological consequences. Autoimmun Rev 2010;9:425-430.

6 6 Munoz LE, Lauber K, Schiller M, Manfredi AA, Herrmann M: The role of defective clearance of apoptotic cells in systemic autoimmunity. Nat Rev Rheumatol 2010;6:280-289.

7 D'Cruz DP, Khamashta MA, Hughes GR: Systemic lupus erythematosus. Lancet 2007;369: 587-596.

8 Korb LC, Ahearn JM: C1q binds directly and specifically to surface blebs of apoptotic human keratinocytes: complement deficiency and systemic lupus erythematosus revisited. J Immunol 1997;158:4525-4528.

-9 Pickering MC, Botto M, Taylor PR, Lachmann PJ, Walport MJ: Systemic lupus erythematosus, complement deficiency, and apoptosis. Adv Immunol 2000;76:227-324.

10 Galvan MD, Foreman DB, Zeng E, Tan JC, Bohlson SS: Complement component $\mathrm{Clq}$ regulates macrophage expression of Mer tyrosine kinase to promote clearance of apoptotic cells. J Immunol 2012;188:3716-3723.

11 Shapiro L, Scherer PE: The crystal structure of a complement-1q family protein suggests an evolutionary link to tumor necrosis factor. Curr Biol 1998;8:335-338.

-12 Schaffler A, Buechler C: CTRP family: linking immunity to metabolism. Trends Endocrinol Metab 2012;23:194-204.

13 Parker J, Menn-Josephy H, Laskow B, Takemura Y, Aprahamian T: Modulation of lupus phenotype by adiponectin deficiency in autoimmune mouse models. J Clin Immunol 2011;31:167-173.

14 Aprahamian T, Bonegio RG, Richez C, Yasuda K, Chiang LK, Sato K, et al: The peroxisome proliferator-activated receptor $\gamma$ agonist rosiglitazone ameliorates murine lupus by induction of adiponectin. J Immunol 2009; 182:340-346.

15 Kadowaki T, Yamauchi T: Adiponectin and adiponectin receptors. Endocr Rev 2005;26: 439-451.

16 Yamauchi T, Kamon J, Ito Y, Tsuchida A, Yokomizo T, Kita S, et al: Cloning of adiponectin receptors that mediate antidiabetic metabolic effects. Nature 2003;423:762-769.

17 Awazawa M, Ueki K, Inabe K, Yamauchi T, Kubota N, Kaneko K, et al: Adiponectin enhances insulin sensitivity by increasing hepatic IRS-2 expression via a macrophage-derived IL-6-dependent pathway. Cell Metab 2011; 13:401-412.

18 Heiker JT, Kosel D, Beck-Sickinger AG: Molecular mechanisms of signal transduction via adiponectin and adiponectin receptors. Biol Chem 2010;391:1005-1018.

19 Carling D, Thornton C, Woods A, Sanders MJ: AMP-activated protein kinase: new regulation, new roles? Biochem J 2012;445:11-27.

20 Sag D, Carling D, Stout RD, Suttles J: Adenosine $5^{\prime}$-monophosphate-activated protein kinase promotes macrophage polarization to an anti-inflammatory functional phenotype. J Immunol 2008;181:8633-8641.

21 Mounier R, Theret M, Arnold L, Cuvellier S, Bultot L, Goransson O, et al: AMPKa1 regulates macrophage skewing at the time of resolution of inflammation during skeletal muscle regeneration. Cell Metab 2013;18:251-264.

22 Jiang S, Park DW, Stigler WS, Creighton J, Ravi S, Darley-Usmar V, et al: Mitochondria and AMP-activated protein kinase-dependent mechanism of efferocytosis. J Biol Chem 2013;288:26013-26026.

23 Tenner AJ, Lesavre PH, Cooper NR: Purification and radiolabeling of human C1q. J Immunol 1981;127:648-653.

24 Young KR Jr, Ambrus JL Jr, Malbran A, Fauci AS, Tenner AJ: Complement subcomponent C1q stimulates Ig production by human B lymphocytes. J Immunol 1991;146:33563364.

25 Roach T, Slater S, Koval M, White L, Cahir McFarland ED, Okumura M, et al: CD45 regulates Src family member kinase activity associated with macrophage integrin-mediated adhesion. Curr Biol 1997;7:408-417.

26 Bohnsack JF, Kleinman HK, Takahashi T, O'Shea JJ, Brown EJ: Connective tissue proteins and phagocytic cell function: laminin enhances complement and Fc-mediated phagocytosis by cultured human macrophages. J Exp Med 1985;161:912-923.

27 Lillis AP, Greenlee MC, Mikhailenko I, Pizzo SV, Tenner AJ, Strickland DK, et al: Murine low-density lipoprotein receptor-related protein 1 (LRP) is required for phagocytosis of targets bearing LRP ligands but is not required for C1q-triggered enhancement of phagocytosis. J Immunol 2008;181:364-373.

28 Bolstad BM, Irizarry RA, Astrand M, Speed TP: A comparison of normalization methods for high density oligonucleotide array data based on variance and bias. Bioinformatics 2003; 19:185-193.

29 Storey JD, Tibshirani R: Statistical significance for genomewide studies. Proc Nat Acad Sci USA 2003;100:9440-9445.

- 30 Bobak DA, Gaither TA, Frank MM, Tenner AJ: Modulation of FcR function by complement: subcomponent $\mathrm{Clq}$ enhances the phagocytosis of IgG-opsonized targets by human monocytes and culture-derived macrophages. J Immunol 1987;138:1150-1156.

31 Arora M, Munoz E, Tenner AJ: Identification of a site on mannan-binding lectin critical for enhancement of phagocytosis. J Biol Chem 2001;276:43087-43094.

-32 Takemura Y, Ouchi N, Shibata R, Aprahamian T, Kirber MT, Summer RS, et al: Adiponectin modulates inflammatory reactions via calreticulin receptor-dependent clearance of early apoptotic bodies. J Clin Invest 2007;117: 375-386.

33 Ohashi K, Parker JL, Ouchi N, Higuchi A, Vita JA, Gokce N, et al: Adiponectin promotes macrophage polarization toward an anti-inflammatory phenotype. J Biol Chem 2010;285:6153-6160.
34 Yamauchi T, Kadowaki T: Adiponectin receptor as a key player in healthy longevity and obesity-related diseases. Cell Metab 2013;17: 185-196.

35 Majai G, Sarang Z, Csomos K, Zahuczky G, Fesus L: PPAR $\gamma$-dependent regulation of human macrophages in phagocytosis of apoptotic cells. Eur J Immunol 2007;37:13431354.

36 Roszer T, Menendez-Gutierrez MP, Lefterova MI, Alameda D, Nunez V, Lazar MA, et al: Autoimmune kidney disease and impaired engulfment of apoptotic cells in mice with macrophage peroxisome proliferator-activated receptor $\gamma$ or retinoid $\mathrm{X}$ receptor a deficiency. J Immunol 2011;186: 621-631.

-37 A-Gonzalez N, Bensinger SJ, Hong C, Beceiro S, Bradley MN, Zelcer N, et al: Apoptotic cells promote their own clearance and immune tolerance through activation of the nuclear receptor LXR. Immunity 2009;31:245-258.

38 Mukundan L, Odegaard JI, Morel CR, Heredia JE, Mwangi JW, Ricardo-Gonzalez RR, et al: PPAR- $\delta$ senses and orchestrates clearance of apoptotic cells to promote tolerance. Nat Med 2009;15:1266-1272.

39 Botto M, Dell'Agnola C, Bygrave AE, Thompson EM, Cook HT, Petry F, et al: Homozygous $\mathrm{C} 1 \mathrm{q}$ deficiency causes glomerulonephritis associated with multiple apoptotic bodies. Nat Genet 1998;19:56-59.

40 Mitchell DA, Pickering MC, Warren J, Fossati-Jimack L, Cortes-Hernandez J, Cook HT, et al: C1q deficiency and autoimmunity: the effects of genetic background on disease expression. J Immunol 2002;168:2538-2543.

-41 Yokota T, Oritani K, Takahashi I, Ishikawa J, Matsuyama A, Ouchi N, et al: Adiponectin, a new member of the family of soluble defense collagens, negatively regulates the growth of myelomonocytic progenitors and the functions of macrophages. Blood 2000;96:17231732.

42 Ogden CA, deCathelineau A, Hoffmann PR, Bratton D, Ghebrehiwet B, Fadok VA, et al: $\mathrm{Clq}$ and mannose binding lectin engagement of cell surface calreticulin and CD91 initiates macropinocytosis and uptake of apoptotic cells. J Exp Med 2001;194:781-795.

43 Vandivier RW, Ogden CA, Fadok VA, Hoffmann PR, Brown KK, Botto M, et al: Role of surfactant proteins $\mathrm{A}, \mathrm{D}$, and $\mathrm{C} 1 \mathrm{q}$ in the clearance of apoptotic cells in vivo and in vitro: calreticulin and CD91 as a common collectin receptor complex. J Immunol 2002;169:39783986.

44 Nauta AJ, Castellano G, Xu W, Woltman AM, Borrias MC, Daha MR, et al: Opsonization with $\mathrm{C} 1 \mathrm{q}$ and mannose-binding lectin targets apoptotic cells to dendritic cells. J Immunol 2004; 173:3044-3050.

45 Reidy MF, Wright JR: Surfactant protein A enhances apoptotic cell uptake and TGF- $\beta 1$ release by inflammatory alveolar macrophages. Am J Physiol Lung Cell Mol Physiol 2003;285:L854-L861. 
46 Kuraya M, Ming Z, Liu X, Matsushita M, Fujita T: Specific binding of $\mathrm{L}-$ ficolin and $\mathrm{H}-\mathrm{fi}-$ colin to apoptotic cells leads to complement activation. Immunobiology 2005;209:689697.

47 Jensen ML, Honore C, Hummelshoj T, Hansen BE, Madsen HO, Garred P: Ficolin-2 recognizes DNA and participates in the clearance of dying host cells. Mol Immunol 2007; 44:856-865.

48 Honore C, Hummelshoj T, Hansen BE, Madsen $\mathrm{HO}$, Eggleton P, Garred P: The innate immune component ficolin 3 (hakata antigen) mediates the clearance of late apoptotic cells. Arthritis Rheum 2007;56:1598-1607.
49 Ramirez-Ortiz ZG, Pendergraft WF 3rd, Prasad A, Byrne MH, Iram T, Blanchette CJ, et al: The scavenger receptor SCARF1 mediates the clearance of apoptotic cells and prevents autoimmunity. Nat Immunol 2013;14: 917-926.

50 Bae HB, Zmijewski JW, Deshane JS, Tadie JM, Chaplin DD, Takashima S, et al: AMP-activated protein kinase enhances the phagocytic ability of macrophages and neutrophils. FASEB J 2011;25:4358-4368.

51 Han CZ, Ravichandran KS: Metabolic connections during apoptotic cell engulfment. Cell 2011;147:1442-1445.
52 Park D, Han CZ, Elliott MR, Kinchen JM, Trampont PC, Das S, et al: Continued clearance of apoptotic cells critically depends on the phagocyte Ucp2 protein. Nature 2011; 477:220-224

53 Mihaylova MM, Shaw RJ: The AMPK signalling pathway coordinates cell growth, autophagy and metabolism. Nat Cell Biol 2011;13: 1016-1023.

54 Nagy L, Szanto A, Szatmari I, Szeles L: Nuclear hormone receptors enable macrophages and dendritic cells to sense their lipid environment and shape their immune response. Physiol Rev 2012;92:739-789. 